\section{Systematic views}

\section{Adrian Friday}

Cladistics: The International Journal of the Willi Hennig Society. Editors N.I. Platnick and C.J. Humphries. Meckler, Grosvenor Gardens House, Grosvenor Gardens, London SWIW OBS. 4/yr. $£ 80, \$ 95$.

WhEN Cladistics first appeared in late 1985, its subtitle - The International Journal of the Willi Hennig Society - left no doubt in many minds as to what the content of the new journal was likely to be. There can be few biologists who are not aware of the controversies surrounding the development of cladistic methodology. Many of these controversies turn out to be less exciting than at first sight; rather. they are usually the result of misunderstandings and distortions.

A recent issue provides a statement of the nature of and need for Cladistics. The emphasis is on the scientific status of cladistic methodology (in the sense of "prediction, analysis and test"), its explicit nature (". . . this new systematics does not have to rely on authority, tradition. idiosyncrasy or irrational criteria") and its deployment in fields other than biology. The subject itself is summarized as dealing with "homology, its evaluation and parsimonious interpretation".

The journal aims to publish papers on theory, method, congruence studies and application studies in morphology, molecular biology, botany, zoology, linguistics, ontogeny, biogeography and systematic philosophy. Recent papers have ranged from the exclusively philosophical or mathematical to those dealing with detailed aspects of the comparative morphology and biogeography of particular groups. Not much molecular biology has so far been in evidence.

Since its origin the journal has been edited by N.I. Platnick of the American Museum of Natural History, a zoologist, and C.J. Humphries of the British Museum (Natural History), a botanist. The assistant editors are also one from each of these institutions. Each issue has approximately 100 pages made up of three sections: first the papers themselves, taking up about half or more of the issue, then a "forum" and finally book reviews. In the forum section some contributions are intended to provoke new discussion, others take up points made in papers

\section{Lines of sight}

\section{Stuart Sutherland}

Spatial Vision. Editors-in-chief P.C. Dodwell and D.H. Foster. $V N U$. $4 / y r$. Price DM 250.

FOR many years scientific publishing houses have vied with one another to produce new learned journals, not without cause for it is a highly profitable enterprise. Now VNU Science Press has found yet another 'gap in the market'. Spatial Vision presumably means the processing of visual stimuli in so far as it is affected by their two- or three-dimensional arrangements in space, including the part of the visual field in which they lie.

As is still de rigeur, Spatial Vision is 'interdisciplinary', though it turns out that the different disciplines are separated only by a hair's breadth. They are visual psychophysics (the experimental study of the quantitative relationships between the physical stimulus and the experience it produces), cognitive or high-level visual processing and theoretical studies using computer simulation or mathematical techniques. Some examples of the three disciplines taken from the journal itself are, respectively, visual acuity, the recognition of simple figures, and computational methods of extracting the lines present in moiré patterns.

Perhaps the most laudable feature of the enterprise is that the editors promise to make mathematical treatments available to the humble experimentalist. Unfortunately this is no easy task, and it is doubtful whether experimentalists will be fooled into thinking they have understood a piece of mathematics simply through the device of putting the more formidable equations in an appendix.

The articles appear to have been well edited and most are as clear as they could be given the difficulty of the subject. On the other hand the great majority stick to effect or the number of spatial frequency channels. The results rarely come as a surprise. But in a notable exception, V.S. Ramachandran and V. Inada demonstrate that the motion seen in successive presentations of random dot patterns follows the motion of their edges if the edges are shifted or even of a background pattern of moving stripes. This is a further complication with which theories of motion detection will have to deal.

The journal is worthy and competent though expensive. But after all, who can blame publishers for making hay in the sunshine that remains before the arrival of the computer winter, when by tapping a few keys we shall be able to receive for nothing, or almost nothing, a VDU display of any paper we fancy.

Stuart Sutherland is Director of the Centre for Research on Perception and Cognition, University of Sussex, Brighton BNI 9QG, UK. well-worn themes, such as the tilt after- published in previous issues, and there are also reports of scientific meetings. No dates for receipt or revision of papers are given, but the turnaround seems to be relatively rapid.

One criticism of the journal is that it tends to be inward looking. Given its partisan nature it is perhaps not surprising that there are instances of homeliness, self-congratulation, condescension and sometimes descent into downright invective. These are the least welcome aspects of the journal's current style, but at least it

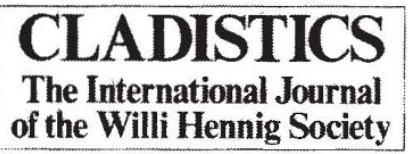

wears its heart on its sleeve and this does no great harm so long as it does not frighten away newcomers to the trade or those from non-biological disciplines whom the journal would like to attract. Papers critical of cladistics certainly have been published, but they are often followed, in subsequent issues, by forum contributions written in apoplectic incredulity - a sort of trans-Atlantic version of "Yours disgusted".

Cladistics, then, is nothing if not lively, and the editors must sometimes need to be very robust. In many ways the journal caters for cladists who previously would have relied on Systematic Zoology to publish articles and discussion of special interest to them. It has carried some substantial and fascinating contributions, and does clearly fill a publishing need.

Adrian Friday is at the University Museum of Zoology, University of Cambridge, Downing Street, Cambridge CB2 3 EJ, UK.

\section{At the bottom}

\section{Patrick D. Armitage}

Journal of the North American Benthological Society. Managing editor Rosemary J. Mackay. North American Benthological Society, 1,041 New Hampshire Street, Lawrence, Kansas 66044. 4/yr. \$50 (institutional); $\$ 15$ (individual, NABS members).

The North American Benthological Society (NABS) is one of the largest and most active groups of freshwater biologists in the world, and a journal affiliated to the society is long overdue. The journal's aim is to promote further understanding of benthic communities and their role in aquatic systems. Emphasis is placed on inland freshwater habitats but there is provision to accept papers on estuarine and marine topics. Theoretical discussions and critical appraisals of rapidly developing research fields are also considered, although none appeared in the first volume.

In the four issues provided for review a 